\title{
Bioaugmented Hydrogen Production from Lignocellulosic Substrates Using Co-Cultures of Shigella flexneri str. G3 and Clostridium acetobutylicum X9
}

\author{
Cristiano Varrone ${ }^{a, b, \#}$, Lingfang Gao ${ }^{c, \#, *}$, Tao Sheng ${ }^{a}$, Chong Liu ${ }^{a}$, Chuang Chen ${ }^{a}$, \\ Wenzong $\mathrm{Liu}^{\mathrm{c}}$ and Aijie Wang ${ }^{\mathrm{a}, \mathrm{c},{ }^{*}}$
}

\author{
${ }^{a}$ State Key Laboratory of Urban Water Resource and Environment, Harbin Institute of Technology \\ (SKLUWRE, HIT), PR China \\ ${ }^{b}$ ENEA-Italian Agency for New Technologies, Energy and Sustainable Development (UTRINN-BIO), Rome, \\ Italy \\ ${ }^{c}$ Research Center for Eco-Environmental Sciences, Chinese Academy of Sciences, Beijing, China
}

\begin{abstract}
Bioaugmented fermentation of cellulosic substrates to produce biohydrogen via co-culture of isolated strains was investigated. Two mesophilic anaerobic bacterial strains, known for their ability to hydrolyze cellulosic substrates, were taken in consideration: Shigella flexneri str. G3, which shows high cellulolytic activity but cannot ferment oligosaccharides to bioenergy, and Clostridium acetobutylicum X9, able to convert microcrystalline cellulose into hydrogen. The ability of the selected strains to effectively convert different cellulosic substrates to hydrogen was tested on carboxymethyl cellulose (AVICEL), as well as pretreated lignocellulosic material such as Bermuda grass, corn stover, rice straw, and corn cob. Results showed that co-culture of Shigella flexneri str G3 and Clostridium acetobutylicum X9 efficiently improved cellulose hydrolysis and subsequent hydrogen production from carboxymethyl cellulose. Hydrogen production yield was enhanced from $0.65 \mathrm{~mol} \mathrm{H}_{2}$ (mol glucose) $)^{-1}$ of the $\mathrm{X} 9$ single culture to approximately $1.5 \mathrm{~mol} \mathrm{H}_{2}$ (mol glucose) $)^{-1}$ of the co-culture, while the cellulose degradation efficiency increased from $50 \%$ to $95 \%$. Co-culture also efficiently improved hydrogen production from natural lignocellulosic materials (which was up to 4-5 times higher than mono-culture with X9), with the highest performance of $24.8 \mathrm{mmol} \mathrm{L}^{-1}$ obtained on Bermuda grass. The results demonstrate that co-culture of $S$. flexneri $\mathrm{G} 3$ and $C$. acetobutylicum X9 was capable of efficiently enhance cellulose conversion to hydrogen, thus fostering potential biofuel applications under mesophilic conditions.
\end{abstract}

Keywords: Bioaugmentation, co-culture, lignocelluloses, saccharification, biohydrogen.

\section{INTRODUCTION}

Production of renewable fuels such as bio-hydrogen from lignocellulosic biomass holds remarkable potential to meet the current energy demand, as well as to mitigate greenhouse gas emissions for a sustainable environment [1-2]. The use of lignocellulosic substrates is thus very promising and might provide abundant non-food feedstocks for the production of secondgeneration biofuels, with environmental benefits and large net energy gains [3]. In fact, biomass-derived saccharides such as glucose, cellobiose and other minor sugars, can be readily fermented by appropriate microbes into bioenergy products and other commodity chemicals [4]. Nonetheless, how to effectively convert lignocellulosic materials to sugars is the bottleneck in cellulosic biofuels industry [5-6].

Lignocellulosic biofuels can only be competitive on an industrial scale if efficient and viable technologies can be developed [7-9]. Combining hydrolysis of

*Address correspondence to these authors at the Research Center for EcoEnvironmental Sciences, Chinese Academy of Sciences, Beijing, China; Tel: +86-451-86282195; Fax: ++86-451-86282195; E-mails: Ifgao@rcees.ac.cn, ajwang@rcees.ac.cn

\#These two authors contributed equally. cellulose with simultaneous fermentation of oligosaccharides in a single process, i.e. direct microbial conversion (DMC), is an ideal strategy for converting cellulosic biomass to bioenergy (i.e $\mathrm{H}_{2}$ or ethanol). However, no single microorganisms/communities can implement DMC with a high efficiency [10]. Thus, a combination of high-active cellulose hydrolyzing bacteria and hydrogen-producing bacteria could result in a more efficient hydrogen production from cellulosic materials. Liu et al. (2003), for instance, reported that their mixed culture, comprising microbes closely affiliated with the genus Thermoanaerobacterium, produced $7.56 \mathrm{mg} \mathrm{H}_{2} \mathrm{~g}$ cellulose from a $5 \mathrm{~g}$ cellulose $\mathrm{l}$ ${ }^{1}$ suspension, maintained at $55{ }^{\circ} \mathrm{C}$ [11]; while Liu and colleagues (2008) showed that the mixed culture of Clostridium thermocellum JN4 and Thermoanaerobacterium thermosaccharolyticum GD17 was able to produce $1.8 \mathrm{~mol} \mathrm{H}_{2}$ (mol glucose) $)^{-1}$ from $5 \mathrm{~g} \mathrm{l}^{-1}$ carboxymethyl cellulose [12].

Although thermophilic bacteria are widely used in cellulosic-hydrogen processes (carried out at high temperatures), mesophilic organisms would help reducing operational costs, and are important for many industrial processes, typically carried out at room 
temperature [13] or slightly higher. However, cellulose hydrolysis under mesophilic conditions is generally slower and less efficient. For instance, Ren and colleagues reported that the hydrogen yield by Clostridium populeti from $7.8 \mathrm{~g} / \mathrm{l}$ cellulose at $37^{\circ} \mathrm{C}$ was 1.4 (mol glucose) $^{-1}$ [14]; Clostridium butyricum CGS5 exhibited $\mathrm{H}_{2}$ production from rice husk hydrolysates with a $\mathrm{H}_{2}$ yield of $17.24 \mathrm{mmol} \mathrm{H} 2$ (g cellulose) ${ }^{-1}$ [15]. Lo et al. [16] investigated the cellulosic-hydrogen production from mixed bacterial Clostridium species consortia. The results showed consortia NS hydrolyzed $10 \mathrm{~g} / \mathrm{L} \mathrm{CMC}$ to produce $0.097 \mathrm{mmol} \mathrm{H} / \mathrm{g}$ cellulose at $35^{\circ} \mathrm{C}$.

In a previous study we reported that Shigella flexneri str. G3 exhibits high hydrolytic activity and oligosaccharides production capability under mesophilic conditions: oligosaccharide production yield reached $375 \mathrm{mg} \mathrm{g}^{-1}$ Avicel [13]. To our knowledge, this represents the highest oligosaccharide yield and specific rate from cellulose for mesophilic bacterial monocultures reported so far. However, no bioenergy products (i.e. hydrogen, ethanol, biodiesel) were generated by $S$. G3 [13]. On the other hand, Clostridium acetobutylicum $\mathrm{X} 9$, another strain isolated from our lab [17], produced hydrogen directly from cellulose (AVICEL) at $37^{\circ} \mathrm{C}$.

The overall aim of this study was to evaluate the effect of bioaugmentation on the ability of converting cellulose to hydrogen under mesophilic conditions. To do so, the mesophilic cellulolytic bacterium Shigella flexneri str. G3, which is capable of rapid and efficient production of sugars from cellulose, was put in coculture with the hydrogen-producing Clostridium acetobutylicum $\mathrm{X9}$, in order to investigated their joint cellulose hydrolysis and hydrogen production performance.

\section{MATERIALS AND METHODS}

\subsection{Strains and Medium}

The two bacterial strains used in this study were previously isolated at our laboratory. Shigella flexneri str. G3 is a gram-negative, short rod-shaped, nonmotile bacterium (Figure S1a), which was isolated from rumen liquor [13]. It exhibits high hydrolytic activity (cellulose degradation reaching around $75 \%$ ) and among the highest oligosaccharide yields from cellulose, under mesophilic conditions. Oligosaccharides generated by G3 are mainly composed of glucose $(30 \%)$ and cellobiose $(70 \%)$, probably related to the low $\beta$-glucosidase activity [13]. However, as already mentioned, Shigella flexneri str. G3 is not able to produce hydrogen. Clostridium acetobutylicum X9 (Figure S1b), a cellulosic-hydrogen producing fermentative bacteria, was isolated from a continuous flow anaerobic reactor fed with molasses (Wang et al., 2008). The strain has regular rod cells without flagellum and is able to rapidly utilize a large variety of pure cellulose, di-/tri-saccharides and monosaccharides to grow. A previous study showed an appreciable Avicel degradation ability [18]. Besides Avicel, $\mathrm{X} 9$ is also able to utilize other substrates, such as glucose, cellobiose, lactose, maltose, fructose, mannose as carbon sources to produce hydrogen. It was thus utilized for co-culture with strain $\mathrm{G} 3$ in fermentation tests.

The Mp medium (modified from ATCC1191 medium) was used for cultivation experiments, containing (per liter): $3.0 \mathrm{~g}$ of Avicel $\mathrm{PH}-101$ (50 $\mu \mathrm{m}$, HukaBiochemika 11365, Sigma-Aldrich Chemie), $1.5 \mathrm{~g}$ of $\mathrm{KH}_{2} \mathrm{PO}_{4}, 4.2 \mathrm{~g}$ of $\mathrm{Na}_{2} \mathrm{HPO}_{4} \cdot 12 \mathrm{H}_{2} \mathrm{O}, 0.5 \mathrm{~g}$ of $\mathrm{NH}_{4} \mathrm{Cl}$, $0.18 \mathrm{~g}$ of $\mathrm{MgCl}_{2} \cdot 6 \mathrm{H}_{2} \mathrm{O}, 1.0 \mathrm{~g}$ of yeast extract, $0.5 \mathrm{~g}$ of $\mathrm{L}$ cysteine, and $1 \mathrm{ml}$ of resazurin $(0.2 \%)$. All the cultivation tests were performed in Vinyl Type A anaerobic chambers (Coy laboratory products, Inc., USA) containing $80 \% \mathrm{~N}_{2}, 20 \% \mathrm{CO}_{2}$ atmosphere, and operated at $37^{\circ} \mathrm{C}$. Bacterial cultures of mid-log phase were transferred into $1 \mathrm{ml}$ vials containing $20 \%(\mathrm{v} / \mathrm{v})$ glycerol and kept in $-80^{\circ} \mathrm{C}$ for future use. A modified $\mathrm{Mp}$ medium, replacing Avicel $\mathrm{PH}-101$ with $1.0 \mathrm{~g}$ of glucose (other gradients kept same), was used as the pre-culture medium for the two individual strains. Initial $\mathrm{pH}$ of medium after autoclave $\left(121^{\circ} \mathrm{C}, 15 \mathrm{~min}\right)$ was 6.8 , and was not controlled nor buffered during the test.

Moreover, hydrolysis and hydrogen production were also tested on pretreated $\left(1.2 \% \mathrm{w} / \mathrm{v} \mathrm{H}_{2} \mathrm{SO}_{4}\right.$ steamexploded) natural lignocellulosic materials, such as Bermuda grass, corn stover, rice straw, and corn cob. Pretreatment was used for lignin depolymerization, thus improving cellulose utilization. Experiments were performed using $5 \mathrm{~g} \mathrm{~L}^{-1}$ of such pretreated substrates, which were obtained according to the method described by Ren and colleagues [17].

\subsection{Co-Culture Test}

The idea of co-culture was to use strain $X 9$ (hydrogen producer) to ferment oligosaccharides generated by G3. Prior to co-culture, the single strains S. G3 and C. X9 were cultured individually with $0.1 \%$ of glucose for 40 hours and 10 hours, respectively. Midlog phase cells were collected, filtered, and washed 
with distilled water for co-culture test. Co-culture tests were performed using the Mp medium as described in the cultivation tests. $150 \mathrm{~mL}$ medium were mixed with $15 \mathrm{ml}$ inoculum containing $0.425 \mathrm{~g}$ dry cells (volume ratio of $\mathrm{G} 3$ and $\mathrm{X} 9: 50 \%: 50 \%$ ), and kept at $37^{\circ} \mathrm{C}$ for 50 h. In order to better evaluate the bioaugmented hydrogen production, mono-culture fermentation with X9 was conducted as control. In the pure culture control test the biomass was adjusted to $0.425 \mathrm{~g}$ dry cells.

Samples were taken every $5 \mathrm{hrs}$ for a 50 -hour incubation period, to determine cell biomass, $\mathrm{pH}$ change, hydrogen yield, cellulose degraded, saccharide yield, and liquid end products.

\subsection{Analytical Procedures}

Cell growth on insoluble microcrystalline cellulose was determined indirectly by measuring the total protein after cell-lysis pretreatment using a modified method described by Bradford [19]. The process was as follows: $1 \mathrm{ml}$ mid-log bacterial cell culture with Avicel was collected and centrifuged at the maximum speed $(14,000 \times \mathrm{g})$ for $10 \mathrm{~min}$ at room temperature. After discarding the suspension, $300 \mu \mathrm{l}$ mixture $(0.303 \mathrm{~g}$ of Tris, $0.189 \mathrm{ml}$ of HCl, $0.8 \mathrm{~g}$ of SDS dissolved in $10 \mathrm{ml}$ of ultra-pure water) was added to the pellet, and incubated at $100^{\circ} \mathrm{C}$ for $20 \mathrm{~min}$. After cooling, the supernatant was separated by centrifugation at the maximum speed $(14,000 \times \mathrm{g})$ at room temperature, and used to determine cellular protein content using the Bradford method [19]. A standard curve was generated using a series of concentrations of bovine serum albumin (BSA) solutions as standards. Absorbance was measured in triplicate at $595 \mathrm{~nm}$ after $20 \mathrm{~min}$ of incubation at room temperature.

Cellulose concentration was determined using the method of Huang and colleagues [20]. Residual cellulose was washed by using acetic acid - nitric acid reagent and water to remove non-cellulosic materials, as described by Updegraff [21]. Cellulose was then quantified using the phenol-sulfuric acid method [22], with glucose as the standard. Saccharides and liquid end products, such as volatile fatty acids (VFA), were determined by a Hewlett-Packard HPLC chromatograph (HP1090) equipped with a refractive index and UV detector $(\lambda=210 \mathrm{~nm})$, using a solution of $5 \mathrm{mN}$ $\mathrm{H}_{2} \mathrm{SO}_{4}$ (mobile phase) as described elsewhere [23]. Avicel hydrolysis ratio \% was estimated as the fraction of the cellulose that was consumed, given as a percent of the total provided as substrate. Oligosaccharide yields were calculated as the amount of oligosaccharides produced (mg) per Avicel added (g). The gas composition was measured using methods previously described by Wang et al. [18]. Yields of hydrogen $\left(\mathrm{Y}_{\mathrm{H} 2}\right)$ were indicated as moles of hydrogen produced per mole of glucose equivalents. The microcrystalline cellulose was considered as a polysaccharide with the formula $\left(\mathrm{C}_{6} \mathrm{H}_{10} \mathrm{O}_{5}\right)_{n}$. The amount of glucose equivalents was calculated based on molecular weight of the monosaccharide molecule of microcrystalline cellulose.

\subsection{Carbon Mass Balance}

Carbon mass balance closure was calculated as output carbon mass divided by input carbon mass [24]:

$$
\text { Closure }(\%)=\frac{\text { carbone coverd }\left[\sum \text { Cout }\right](g)}{\text { initial coverd }\left[\sum \operatorname{Cin}\right](g)} \times 100
$$

The carbon contribution from the medium components is shown in Table S1. The estimation of carbon mass balance for cellulose degradation on Avicel requires the information on initial and final carbon contribution, including cellulose concentrations, cell mass concentrations, soluble protein concentrations, concentrations of saccharides, cumulative gaseous carbon dioxide production (total $\mathrm{CO}_{2}$ ), and byproducts (organic acids). All the parameters were measured immediately after inoculation and thereafter every five hours until the end of the cultivation. Measured methods of carbon content from all sources can be found in our previous study [13].

\section{RESULTS AND DISCUSSION}

\subsection{Cellulose Utilization and Oligosaccharides Production}

Co-culture with $\mathrm{G} 3$ and $\mathrm{X} 9$ was able to complete the fermentation process within $45 \mathrm{~h}$, generating a cellulose utilization quantity of $2.85 \mathrm{~g}(95 \%)$ (Figures 1 and 2). Glucose was undetectable and cellobiose kept a trace level of $3 \mathrm{mg} \mathrm{g}^{-1}$ Avicel, suggesting that oligosaccharides were completely converted. As a comparison, the cellulose utilization ratio of $\mathrm{X} 9$ monoculture reached $50 \%(1.5 \mathrm{~g})$ in $8 \mathrm{~h}$ and did not further increase with time. Cell proteins produced by co-culture of $S$. flexneri $\mathrm{G} 3$ and $C$. acetobutylicum X9 were 0.683 $\mathrm{gl}^{-1}$ total proteins (Figure 1).

These results suggest that cooperation within the co-culture $(\mathrm{G} 3+\mathrm{X} 9)$ might indeed improve substrate 


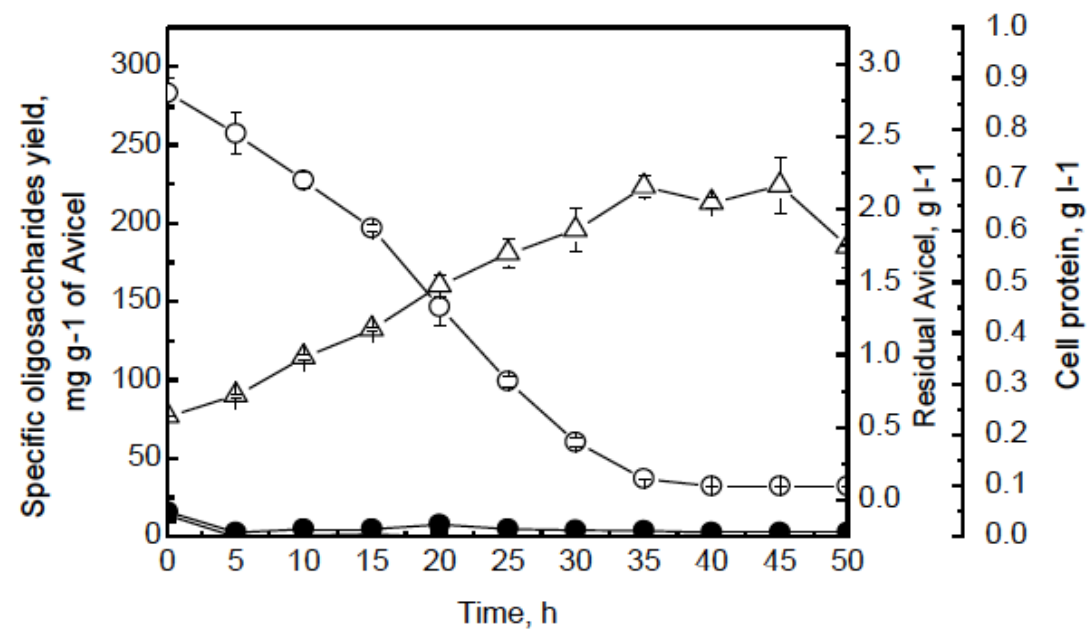

Figure 1: Kinetics of Avicel degradation over time during co-culture tests with strains G3 + X9. Specific oligosaccharides yield (घ, glucose; $\bullet$, cellobiose, left $Y$-axis), residual cellulose ( $\circ$, right $Y$-axis), and cellular protein $(\triangle$, $Y$-axis) by co-cultured strains $\mathrm{G} 3+\mathrm{X} 9$, grown at $3.0 \mathrm{~g} \mathrm{~L}^{-1}$ of Avicel $\mathrm{PH}-101$, in $50 \mathrm{~h}$ of batch fermentation tests. Data are presented as the mean of triplicate cultures with standard deviations (error bars).

degradation efficiency, as well as the kinetics. Clearly, the incomplete utilization of the substrate $(2.25 \mathrm{~g}$ of Avicel utilization in $60 \mathrm{~h}$ ) observed in $\mathrm{G} 3$ in the previous study [13] could also be related to the accumulation of inhibitory compounds in medium or cells [25-26]. In fact, various types of cellulase enzymes can be inhibited by accumulation of soluble products (glucose, cellobiose, cellotriose, etc.) via feedback mechanisms [27]. Thus, in the co-culture test with $G 3+X 9$, the complete conversion of oligosaccharides might have also favored hydrolytic activity, by avoiding feedback inhibition and improving continuous cellulose degradation via S. flexneri G3.

\subsection{Hydrogen Production}

As can be seen in Figure 2, the hydrogen production of co-culture $\mathrm{G} 3+\mathrm{X} 9$, degrading Avicel at 37 C and $\mathrm{pH} 6.7$, reached about $25 \mathrm{mmol}^{-1}$, corresponding to a yield of $1.50 \mathrm{~mol} \mathrm{H}_{2}$ (mol glucose) $)^{-1}$. In comparison, hydrogen production from mono-culture X9 was significantly lower, with $6 \mathrm{mmol} \mathrm{L}^{-1}$, corresponding to a yield of $0.65 \mathrm{~mol} \mathrm{H}_{2}$ (mol glucose $)^{-1}$ ), and diplayed a different time pattern: maximum hydrogen production was reached after 10 hours (with no evident lag-time) and then rapidly decreased, while it kept increasing until $45 \mathrm{~h}$ fermentation in the co-culture. So there was a clear

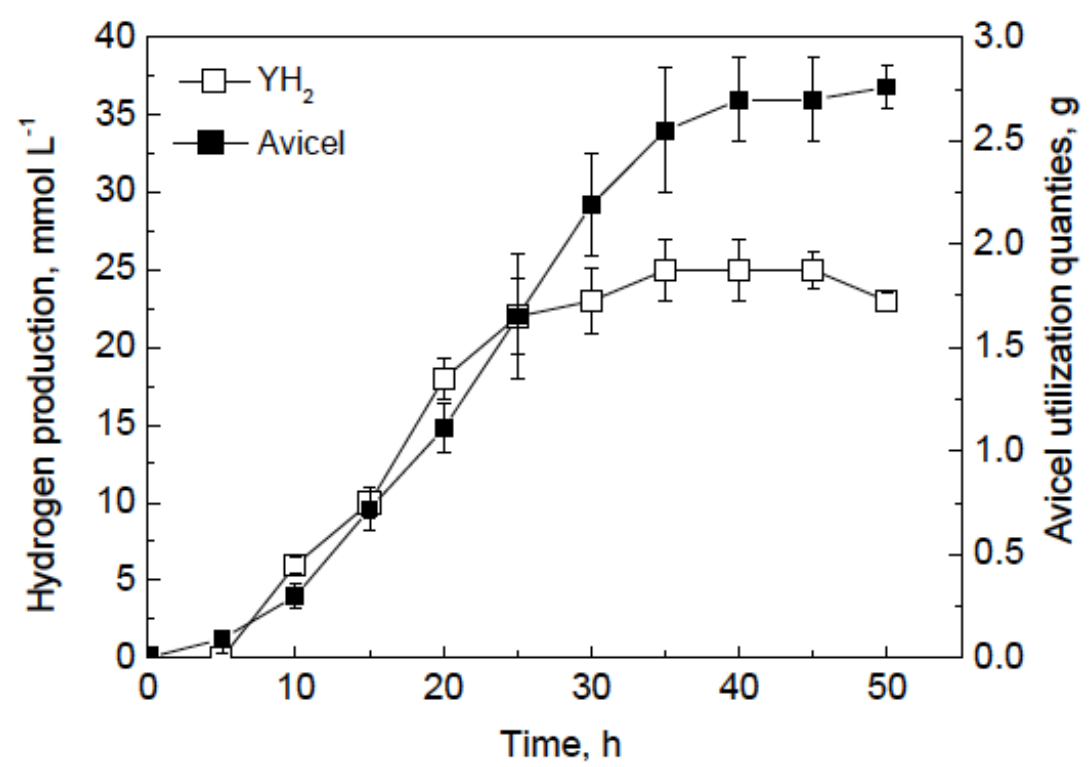

Figure 2: Hydrogen production and cellulose utilization from co-cultured strains $G 3+X 9$ within 50 hrs of batch fermentation time, grown at $3.0 \mathrm{~g} \mathrm{~L}^{-1}$ of Avicel. Data are presented as the mean of triplicate cultures with standard deviations (error bars). 
positive effect on the cellulose utilization / hydrogen production performances in the co-culture $\mathrm{G} 3+\mathrm{X} 9$. The bioaugmented hydrogen production (by $\mathrm{X} 9$ ) was seemingly enhanced by the cellulose hydrolytic role of G3, while on the other hand, the continuous conversion of oligosaccharides (to produce $\mathrm{H} 2$ ) by $\mathrm{X} 9$ might have favoured the hydrolytic activity of $\mathrm{G} 3$, thus suggesting a possible mutual benefit or cooperation of the two strains.

Previous observations showed that G3 monoculture started cellulose degradation only after a lag phase of several hours [13]. Therefore it was probably C. acetobutylicum $\mathrm{X9}$, which started to metabolize Avicel and to grow (producing hydrogen) in the initial stage of the co-culture. After the initial phase, however, the contribution of $\mathrm{G} 3$ to the co-culture seemed to become more evident, seemingly providing an excellent (additional) carbon source for X9, which was able to continue produce hydrogen until $45 \mathrm{~h}$ (while $\mathrm{X} 9$ mono-culture did not show any further hydrogen production already after $10 \mathrm{~h}$ ).

\section{3. pH and Liquid End Products}

The liquid end products of mono-culture $C$. acetobutylicum X9 were primarily composed of acetate and butyrate (Figure 3 ), in accordance with the findings by Wang and colleagues [18]. Acetate and butyrate formation were most probably linked to the hydrogen production (by X9) via butyric acid metabolism. Our results indicated that more organic acids, especially butyrate, acetate and propionate were produced from cellulose degradation and oligosaccharides fermentation during co-culture tests with $G 3+X 9$ (probably due to the a more efficient substrate conversion). Acetate and butyrate showed similar concentration, which increased approximately 3.5 times (each), from less than $350 \mathrm{mg} \mathrm{L}^{-1}$ with $\mathrm{X} 9$ to about $1200 \mathrm{mg} \mathrm{L}^{-1}$ with the co-culture $\mathrm{G} 3+\mathrm{X} 9$, respsctively. Propionate, a typical metabolite from cellulose degradation, was only detected in the co-culture fermentation. Lactate, which is an inhibitor of cellulose degradation [28-29], was also detected during coculture fermentation, but at a lower concentration compared to the other metabolites. The presence of lactate and propionate in the liquid end products was also observed in mono-culture with G3 [13].

The suspension $\mathrm{pH}$ dropped from initial 6.7 to approximately 5.0 in the mono-culture of $\mathrm{X9}$. This $\mathrm{pH}$ drop corresponded to the starting phase for hydrogen production. Similarly, during co-culture tests, the $\mathrm{pH}$ rapidly decreased to $\mathrm{pH} 4.5$ within $20 \mathrm{~h}$ and did not change significantly in the remaining $30 \mathrm{~h}$ fermentation, thus finally reaching $\mathrm{pH}$ 4.3.

\subsection{Carbon Mass Balance}

Carbon balance (C-balance) of co-cutlure $\mathrm{G} 3+\mathrm{X} 9$ was assessed by taking into account Avicel consumption, production of oligosaccharides, liquid end products and $\mathrm{CO}_{2}$, as well as cell biomass (as total protein). As can be observed in Table 1, carbon closure decrease from initial $99.0 \pm 0.01 \%$ (observed at $5 \mathrm{~h}$ ) to $92.8 \pm 0.35 \%$ (after $50 \mathrm{~h}$ ). This trend was in good agreement with the previous study by Wang and colleagues [13], based on strain G3. However,

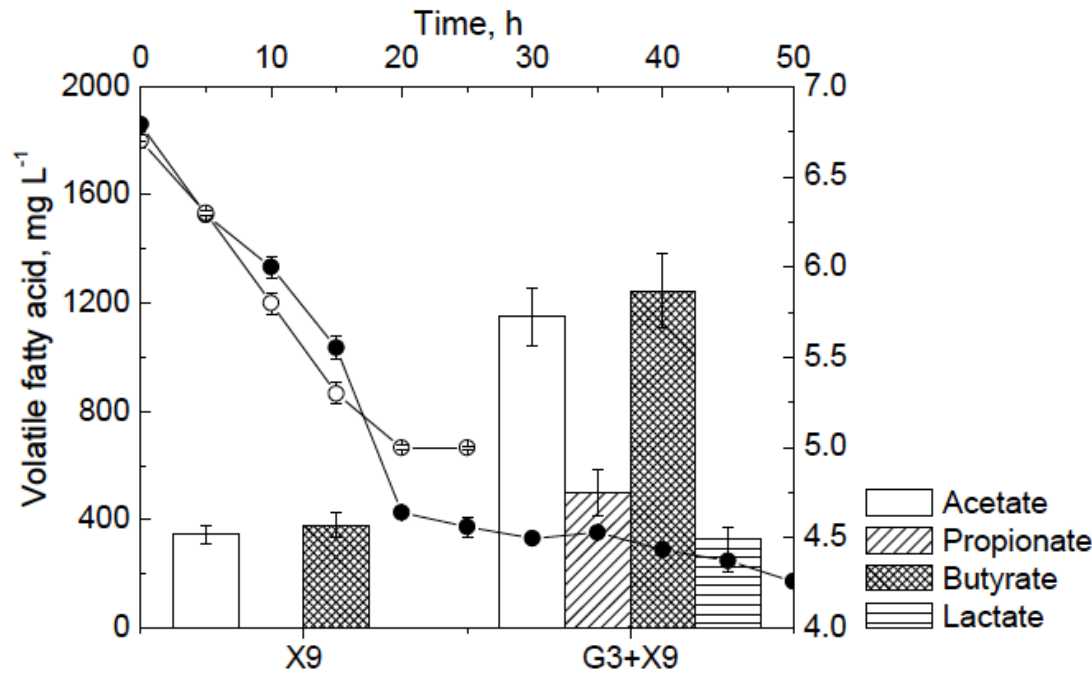

Figure 3: Volatile fatty acid (VFA) and pH profile from mono-culture X9 (o) and co-cultured strains G3 + X9 (•), grown at $3.0 \mathrm{~g}$ $\mathrm{L}^{-1}$ of Avicel, within $50 \mathrm{~h}$ of batch fermentation. Data are presented as the mean of triplicate cultures with standard deviations (error bars). 
Table 1: Average carbon mass allocation for cellulosic-hydrogen runs on Avicel PH-101 substrate by co-culture of S. G3 \& C. X9. Results are shown with \pm 1 standard deviation values for triplicate tubes after $50 \mathrm{~h}$ of incubation and are expressed as $\mathrm{g} C$ per Liter Mp medium

\begin{tabular}{|c|c|c|c|c|c|c|c|c|}
\hline Run time & Avicel & Media & Cell mass & $\begin{array}{c}\text { Soluble } \\
\text { protein }\end{array}$ & Saccharides & CO2 & VFA \\
\hline \hline 0 & $1.29 \pm 0.01$ & $0.16 \pm 0.04$ & $0.23 \pm 0.005$ & 0 & 0 & 0 & 0 \\
\hline $5 \mathrm{~h}$ & $1.22 \pm 0.02$ & $0.13 \pm 0.05$ & $0.23 \pm 0.005$ & $0.01 \pm 0.007$ & 0 & $0.01 \pm 0.001$ & $0.08 \pm 0.002$ & $99.0 \pm 0.01$ \\
\hline $10 \mathrm{~h}$ & $1.00 \pm 0.01$ & $0.08 \pm 0.01$ & $0.25 \pm 0.01$ & $0.01 \pm 0.005$ & $0.01 \pm 0.001$ & $0.05 \pm 0.001$ & $0.35 \pm 0.03$ & $95.9 \pm 0.12$ \\
\hline $15 \mathrm{~h}$ & $0.80 \pm 0.05$ & $0.04 \pm 0.003$ & $0.26 \pm 0.01$ & $0.02 \pm 0.001$ & $0.03 \pm 0.005$ & $0.08 \pm 0.003$ & $0.37 \pm 0.01$ & $95.4 \pm 0.15$ \\
\hline $20 \mathrm{~h}$ & $0.67 \pm 0.02$ & $0.02 \pm 0.005$ & $0.28 \pm 0.05$ & $0.02 \pm 0.003$ & $0.03 \pm 0.002$ & $0.14 \pm 0.005$ & $0.44 \pm 0.03$ & $95.2 \pm 0.12$ \\
\hline $25 \mathrm{~h}$ & $0.45 \pm 0.03$ & 0 & $0.29 \pm 0.02$ & $0.03 \pm 0.001$ & $0.02 \pm 0.008$ & $0.15 \pm 0.02$ & $0.60 \pm 0.05$ & $93.0 \pm 0.20$ \\
\hline $30 \mathrm{~h}$ & $0.27 \pm 0.02$ & 0 & $0.31 \pm 0.02$ & $0.03 \pm 0.002$ & $0.02 \pm 0.005$ & $0.15 \pm 0.08$ & $0.76 \pm 0.04$ & $95.7 \pm 0.20$ \\
\hline $35 \mathrm{~h}$ & $0.11 \pm 0.08$ & 0 & $0.33 \pm 0.03$ & $0.05 \pm 0.002$ & $0.02 \pm 0.001$ & $0.13 \pm 0.02$ & $0.95 \pm 0.02$ & $94.6 \pm 0.45$ \\
\hline $40 \mathrm{~h}$ & $0.07 \pm 0.005$ & 0 & $0.33 \pm 0.02$ & $0.06 \pm 0.002$ & $0.01 \pm 0.003$ & $0.10 \pm 0.003$ & $1.06 \pm 0.01$ & $94.0 \pm 0.38$ \\
\hline $45 \mathrm{~h}$ & $0.06 \pm 0.005$ & 0 & $0.30 \pm 0.05$ & $0.08 \pm 0.004$ & $0.01 \pm 0.003$ & $0.10 \pm 0.005$ & $1.07 \pm 0.01$ & $94.2 \pm 0.34$ \\
\hline $50 \mathrm{~h}$ & $0.06 \pm 0.001$ & 0 & $0.26 \pm 0.04$ & $0.13 \pm 0.03$ & $0.01 \pm 0.001$ & $0.10 \pm 0.002$ & $1.06 \pm 0.02$ & $92.8 \pm 0.35$ \\
\hline
\end{tabular}

differently from the previous study on $G 3$, the carbon balance analysis of the co-culture $X 9+G 3$ indicated that VFAs (and not the oligosaccharides, as in G3) were the dominant component during the fermentation. About $82.2 \%$ of the initial substrate was converted to liquid end products, such as acetate, butyrate, propionate and lactate, and the rest was converted into biomass, trace sugars, proteins and $\mathrm{CO}_{2}$. As a comparison, during the fermentation with $\mathrm{X} 9$ mono-culture, around $28.8 \%$ of initial substrate was converted into VFAs (with a carbon closure of $88.6 \pm 0.43 \%$ at the end of fermentation). The effective conversion of the substrate into VFAs such as acetate and butyrate (by far the biggest fraction of the liquid end products) by the coculture $\mathrm{G} 3+\mathrm{X9}$, without accumulation of oligosacharides, might explain the enhanced overall cellulose conversion efficiency to hydrogen.

\subsection{Hydrolysis of Pretreated Natural Lignocellulosic Substrates and Hydrogen Production}

Mono-culture of $C$. acetobutylicum X9 and the coculture of $S$. flexneri $\mathrm{G} 3$ and $C$. acetobutylicum $\mathrm{X} 9$ were also grown on pretreated lignocellulosic materials. Hydrogen production obtained from the different pretreated lignocellulosic substrates by co-culture G3 + X9 (Figure 4) was: $24.8 \mathrm{mmol} \mathrm{L}^{-1}$ medium (Bermuda grass) $>19.2 \mathrm{mmol} \mathrm{L}^{-1}$ medium (rice straw) $>17.8$ $\mathrm{mmol} \mathrm{L}^{-1}$ medium (corn stover) $>14.4 \mathrm{mmol} \mathrm{L}^{-1}$ medium (corn cob). Noticeably, the hydrogen production from Bermuda grass was similar to that from Avicel (25.3 $\mathrm{mmol} \mathrm{L}^{-1}$; Figure 2). Most likely, the reason for the highest hydrogen production from Bermuda grass was that it has the lowest lignin component $(\sim 2 \%)$ among the four test substrates [30], thus being relatively easier to be decomposed.

The hydrogen yield from natural lignocellulosic material by co-culture G3 + X9 was on average 4-5 times higher than mono-culture with $\mathrm{X} 9$. Moreover, hydrogen was not detected from pretreated corn stover when strain $\mathrm{X} 9$ was cultured alone, while it was produced in co-culture conditions, thus confirming that the co-culture could enhance the hydrogen production ability from lignocellulosic biomass. This preliminary results suggested that $\mathrm{G} 3$ and $\mathrm{X} 9$ may provide useful combinations of metabolic pathways for the processing of complex waste material (and the degradation of impurities and/or inhibitors), thereby supporting a more efficient decomposition of substrate. Similar conclusions were also reported by other authors [3134].

\section{CONCLUSIONS}

This study showed the possibility to effectively enhance biohydrogen production from different cellulosic materials via co-culture of $S$. flexneri G3 and C. acetobutylicum X9. Maximum hydrogen yield on Avicel reached $1.5 \mathrm{~mol} \mathrm{H}_{2}$ (mol glucose) $)^{-1}$, with a cellulose hydrolysis ratio as high as $95 \%$ in $45 \mathrm{~h}$. The corresponding end liquid products were butyrate and acetate, followed by propionate and lactate. Moreover, co-culturing also revealed bioaugmentation effects on biohydrogen production from other cellulosic 


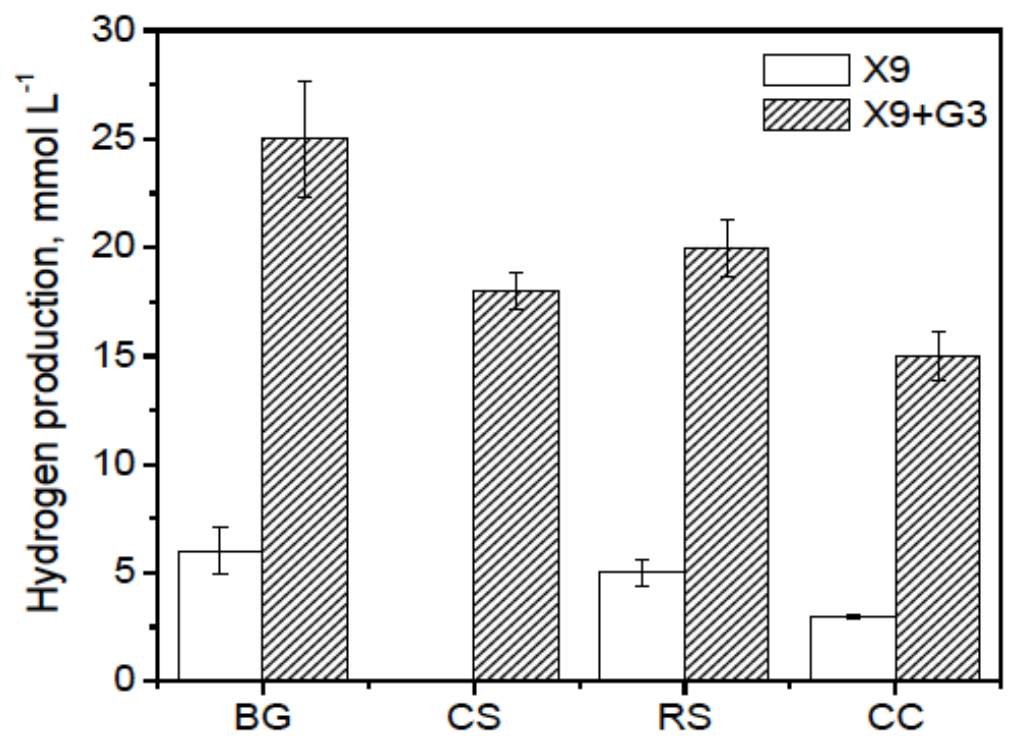

Figure 4: Hydrogen production from pretreated natural lignocellulosic material, using mono-culture $X 9$ and co-cultured strains $(\mathrm{G} 3+\mathrm{X} 9)$ grown at a substrate concentration of $5.0 \mathrm{~g} \mathrm{~L}^{-1} . \mathrm{BG}=$ Bermuda gass; $\mathrm{CS}=$ corn stover; $\mathrm{RS}=$ rice straw; $\mathrm{CC}=\mathrm{corn}$ cob.

substrates, such as pretreated Bermuda grass, corn stover, rice straw and corn cob, with a hydrogen production ranging from $14.4 \mathrm{mmol} \mathrm{L}^{-1}$ to $24.8 \mathrm{mmol}$ $\mathrm{L}^{-1}$. Co-culture efficiently improved hydrogen production by 4-5 times compared to mono-culture with $\mathrm{X} 9$. These results indicated that bioaugmented cultures show an enhanced ability in the conversion of several pretreated lignocellulosic substrates, with a hydrogen production that can be comparable to the one obtained from $(3 \mathrm{~g}$ $\mathrm{L}^{-1}$ ) microcrystalline cellulose. In conclusion we can affirm that co-culture of $S$. flexneri and $\mathrm{G} 3$ \& $C$. acetobutylicum X9 was capable to efficiently enhance cellulose conversion to hydrogen, thus fostering potential biofuel applications under mesophilic conditions.

\section{ACKNOWLEDGEMENTS}

This research was supported by National Natural Science Foundation of China (NSFC, Grant No. 51111140388, No. 51208496), by Science Fund for Creative Research Groups of the National Natural Science Foundation of China (Grant No. 51121062) by China Postdoctoral Science Foundation (No. 2012M510574 and No. 2013T60182). This work was also supported by the State Key Laboratory of Urban Water Resource and Environment (grant no. 2010DX11 and no. 2011TS09).

\section{SUPPLEMENTAL MATERIALS}

The supplemental materials can be downloaded from the journal website along with the article.

\section{REFERENCES}

[1] Levin DB, Zhu H, Beland M, Cicek N, Holbein BE. Potential for hydrogen and methane production from biomass residues in Canada. Bioresour Technol 2007; 98: 654-60. http://dx.doi.org/10.1016/j.biortech.2006.02.027

[2] Howard RL, Abotsi E, Jansen EL, Howard S. Lignocellulose biotechnology: issues of bioconversion and enzyme production. Afr J Biotechnol 2003; 2: 602-19.

[3] Dharmadi Y, Murarka A, Gonzalez R. Anaerobic fermentation of glycerol by Escherichia coli: a new platform for metabolic engineering. Biotechnol Bioeng 2006; 94: 821-9. http://dx.doi.org/10.1002/bit.21025

[4] Parveen K, Barrett D, Delwiche M, Stroeve P. Methods for pretreatment of lignocellulosic biomass for efficient hydrolysis and biofuel prodution. Ind Eng Chem Res 2009; 48: 3713-29. http://dx.doi.org/10.1021/ie801542g

[5] Himmel ME, Ding SY, Johnson DK, Adney WS, Nimlos MR, Brady JW, Foust TD. Biomass recalcitrance: Engineering plants and enzymes for biofuels production. Science 2007; 315: 804-7. http://dx.doi.org/10.1126/science.1137016

[6] Lynd LR, Laser S, Bransby D, et al. How biotech transform biofuels. Nat Biotechnol 2008; 26: 169-72. http://dx.doi.org/10.1038/nbt0208-169

[7] Ingram LO, Gomez PF, Lai X, Moniruzzaman M, Wood BE, Yomano LP, York SW. Metabolic engineering of bacteria for ethanol production. Biotechnol Bioeng 1998; 58: 204-14. http://dx.doi.org/10.1002/(SICl)10970290(19980420)58:2/3<204::AID-BIT13>3.0.CO;2-C

[8] Khan A, Murray W. Single step conversion of cellulose to ethanol by a mesophilic co-culture. Biotech Lett 1982; 4: 17780 http://dx.doi.org/10.1007/BF00144320

[9] Lynd LR, Weimer P, van Zyl WH, Pretorius IS. Microbial cellulose utilization: fundamentals and biotechnology. Microbiol Mol Biol Rev 2002; 66: 506-17. http://dx.doi.org/10.1128/MMBR.66.3.506-577.2002

[10] Wright J, Wyman C, Grohmann K. Simultaneous saccharification and fermentation of lignocelluloses-process evaluation. Appl Biochem Biotechnol 1988; 18: 75-90. http://dx.doi.org/10.1007/BF02930818 
[11] Liu $\mathrm{H}$, Zhang $\mathrm{T}$, Fang $\mathrm{H}$. Thermophilic $\mathrm{H}_{2}$ production from a cellulose-containing wastewater. Biotech Lett 2003; 25: 3659. http://dx.doi.org/10.1023/A:1022341113774

[12] Liu $Y, Y u ~ P$, Song $X, Q u ~ Y$. Hydrogen production from cellulose by co-culture of Clostridium thermocellum JN4 and Thermoanaerobacterium thermosaccharolyticum GD17. Int J Hydrogen Energy 2008; 33: 2927-33. http://dx.doi.org/10.1016/j.ijhydene.2008.04.004

[13] Wang A, Gao L, Ren N, Xu J, Zhou J. Isolation and characterization of Shigella flexneri G3, capable of effective cellulosic saccharification under mesophilic conditions. Appl Environ Microbiol 2011; 77: 517-23. http://dx.doi.org/10.1128/AEM.01230-10

[14] Ren Z, Ward TE, Logan BE, Regan JM. Characterization of the cellulolytic and hydrogen-producing activities of six mesophilic Clostridium species. J Appl Microbiol 2007; 103: 2258-66.

http://dx.doi.org/10.1111/j.1365-2672.2007.03477.x

[15] Lo YC, Saratale D, Chang J. Isolation of cellulose-hydrolytic bacteria and applications of the cellulolytic enzymes for cellulosic biohydrogen production. Enzyme Microbial Technol 2009; 44: 417-25.

http://dx.doi.org/10.1016/j.enzmictec.2009.03.002

[16] Lo YC, Bai M, Chang J. Cellulosic hydrogen production with a sequencing bacterial hydrolysis and dark fermentation strategy. Bioresou Technol 2008; 99: 8299-303. http://dx.doi.org/10.1016/j.biortech.2008.03.004

[17] Ren N, Wang A, Gao L, Xin L, Lee D. Bioaugmented hydrogen production from carboxymethyl cellulose and partially delignified corn stalks using isolatied cultures. Int $\mathrm{J}$ Hydrogen Energy 2008; 33: 5250-55.

http://dx.doi.org/10.1016/j.ijhydene.2008.05.020

[18] Wang A, Ren N, Shi Y, Lee D. Bioaugmented hydrogen production from microcrystalline cellulose using co-cultured Clostridium acetobutylicum $\mathrm{X} 9$ and Ethanoigenens harbineses B49. Int J Hydrogen Energy 2008; 33: 912-7. http://dx.doi.org/10.1016/j.ijhydene.2007.10.017

[19] Bradford MM. A rapid and sensitive method for the quantitation of microgram quantities of protein utilizing the principle of protein-dye binding. Anal Biochem 1976; 72: 24854.

\section{http://dx.doi.org/10.1016/0003-2697(76)90527-3}

[20] Huang L, Gibbins L, Forsberg C. Transmembrane pH gradient and membrane potential in Clostridium acetobutylicum during growth under acetogenic and solventogenic conditions. Appl Environ Microbiol 1985; 50: 1043-7.

[21] Updegraff DM. Semimicro determination of cellulose in biological materials. Anal Biochem 1969; 32: 420-4. http://dx.doi.org/10.1016/S0003-2697(69)80009-6

[22] Dubois M, Gilles K, Hamilton J, Rebers P, Smith F. A colorimetric method for the determination of sugars. Nature 1951; $168: 167$.

http://dx.doi.org/10.1038/168167a0

[23] Varrone C, Giussani B, Izzo G, Massini G, Marone A, Signorini A, Wang A. Statistical optimization of biohydrogen and ethanol production from crude glycerol by microbial mixed culture. Int J Hydrogen Energy 2012; 37: 16479-88. http://dx.doi.org/10.1016/j.ijhydene.2012.02.106

[24] Schell DJ, Sáez JC, Hamilton J, Tholudur A, McMillan JD. Use of measurement uncertainty analysis to assess accuracy of carbon mass balance closure for a cellulose production process. Appl Biochem Biotechnol 2002; 98-100: 509-23. http://dx.doi.org/10.1385/ABAB:98-100:1-9:509

[25] Guedon E, Desvaus M, Payot S, Petitdemange H. Growth inhibition of Clostridium cellulolyticum by an inefficiently regulated carbon flow. Microbiology 1999; 145: 1831-8. http://dx.doi.org/10.1099/13500872-145-8-1831

[26] Guedon E, Payot S, Desvaux M, Petitdemange $H$. Relationships between cellobiose catabolism, enzyme levels, and metabolic intermediates in Clostridium cellulolyticum grown in a synthetic medium. Biotechnol Bioeng 2000; 67: 327-35.

http://dx.doi.org/10.1002/(SICI)10970290(20000205)67:3<327::AID-BIT9>3.0.CO;2-U

[27] Desvaux M, Guedon E, Petitdemange H. Kinetics and metabolism of cellulose degradation at high substrates concentrations in steady-state continuous cultures of Clostridium cellulolyticum on a chemically defined medium. Appl Environ Microbiol 2001; 67: 3837-45. http://dx.doi.org/10.1128/AEM.67.9.3837-3845.2001

[28] Levin B, Islam R, Cicek N, Sparling R. Hydrogen production by Clostridium thermocellum 27405 from cellulosic biomass substrates. Int J Hydrogen Energy 2006; 31: 1496-503. http://dx.doi.org/10.1016/j.ijhydene.2006.06.015

[29] Sparling R, Islam R, Nazim C, Carere C, Chow H, Levin B. Formate synthesis by Clostridium thermocellum during anaerobic fermentation. Can J Microbiol 2006; 52: 681-8. http://dx.doi.org/10.1139/w06-021

[30] Chen F, Dixon R. Lignin modification improves fermentable sugar yields for biofuel production. Nat Biotechnol 2007; 25: 759-61. http://dx.doi.org/10.1038/nbt1316

[31] Marone A, Massini G, Patriarca C, Signorini A, Varrone C Izzo G. Hydrogen production from vegetable waste by bioaugmentation of indigenous fermentative communities. Int J Hydrogen Energy 2012; 37: 5612-22. http://dx.doi.org/10.1016/j.ijhydene.2011.12.159

[32] Rabaey K, Rodriguez J, Blackall LL, Keller J, Gross P, Batstone D, Verstraete W, Nealson KH. Microbial ecology meets electrochemistry: electricity-driven and driving communities. ISME J 2007; 1: 9-18. http://dx.doi.org/10.1038/ismej.2007.4

[33] Sarma SJ, Brar SK, Sydney EB, Le Bihan Y, Buelna G, Soccol CR. Microbial hydrogen production by bioconversion of crude glycerol: a review. Int J Hydrogen Energy 2012; 37: 6473-90.

http://dx.doi.org/10.1016/j.ijhydene.2012.01.050

[34] Varrone C, Rosa S, Fiocchetti F, Giussani B, Izzo G, Marone A, Massini G, Signorini A. Enrichment of activity sludge for enhanced hydrogen production from crude glycerol. Int $J$ Hydrogen Energy 2013; 38: 1319-31.

http://dx.doi.org/10.1016/j.jihydene.2012.11.069 